\title{
Two biochemically distinct lipophosphoglycans from Leishmania braziliensis and Leishmania infantum trigger different innate immune responses in murine macrophages
}

\author{
Izabela Coimbra Ibraim ${ }^{1}$, Rafael Ramiro de Assis ${ }^{1}$, Natália Lima Pessoa', Marco Antônio Campos ${ }^{1}$, \\ Maria Norma Melo ${ }^{2}$, Salvatore Joseph Turco $^{3}$ and Rodrigo Pedro Soares ${ }^{{ }^{*}}$
}

\begin{abstract}
Background: The dominant, cell surface lipophosphoglycan (LPG) of Leishmania is a multifunctional molecule involved in the interaction with vertebrate and invertebrate hosts. Although the role of LPG on infection has been extensively studied, it is not known if LPG interspecies variations contribute to the different immunopathologies of leishmaniases. To investigate the issue of interspecies polymorphisms, two Leishmania species from the New World that express structural variations of side chains of LPG repeat units were examined. In this context, the procyclic form of L. braziliensis LPG (strain M2903), is devoid of side chains, while the L. infantum LPG (strain BH46) has up to three glucoses residues in the repeat units.

Methods: Mice peritoneal macrophages from Balb/c, C57BL/6 and knock-out (TLR2 ${ }^{-/}$, TLR4 $^{-1-}$ ) were primed with IFN- $\gamma$ and stimulated with purified LPG from both species. Nitric oxide and cytokine production, MAPKs (ERK, p38 and JNK) and NF-kB activation were evaluated.

Results: Macrophages stimulated with L. braziliensis LPG, had a higher TNF- $a, I L-1 \beta, I L-6$ and NO production than those stimulated with that of $L$. infantum. Furthermore, the LPGs from the two species resulted in differential kinetics of signaling via MAPK activation. L. infantum LPG exhibited a gradual activation profile, whereas $L$. braziliensis LPG showed a sharp but transient activation. L. braziliensis LPG was able to activate NF-kB.
\end{abstract}

Conclusion: These data suggest that two biochemically distinct LPGs were able to differentially modulate macrophage functions.

Keywords: Leishmania infantum, Leishmania braziliensis, Lipophosphoglycan (LPG), Macrophage modulation

\section{Background}

Leishmaniases are a spectrum of diseases widely distributed in the Americas [1]. In Brazil, Leishmania braziliensis and Leishmania infantum are the causative agents of cutaneous (CL) and visceral leishmaniasis (VL), respectively [2]. At the early steps of infection in the vertebrate host, the parasite must survive the production of inflammatory mediators such as reactive oxygen inter-

\footnotetext{
*Correspondence: rsoares@cpqrr.fiocruz.br

'Centro de Pesquisas René Rachou, Fundação Oswaldo Cruz - FIOCRUZ, Av. Augusto de Lima, 1715, 30190-002, Belo Horizonte, Brazil

Full list of author information is available at the end of the article
}

mediates (ROI), reactive nitrogen intermediates (RNI), and cytokines [3,4].

In trypanosomatids, many GPI-anchored molecules are known to be closely associated with cell signaling, acting as agonists and second messengers in response to cytokines and other stimuli [5-9]. In Leishmania, lipophosphoglycan (LPG) has been extensively studied and is known to be a multifunctional virulence factor with functions that include: attachment to the sand fly vector midgut [10], attachment and entry into macrophages [11], induction of neutrophil extracellular traps (NETs) [12], inhibition of protein kinase C (PKC) [13,14], retardation of phagosome maturation [15], disruption of NADPH oxidase assembly at the 
phagosome membrane [16] modulation of NO production [17] and induction of protein kinase $R$ and heme oxigenase-1 $[18,19]$. Although the lipid anchor is conserved, previous studies have shown that changes in the carbohydrate structure of procyclic LPG and GIPLs can account for variations in macrophage modulation [20-22].

Structurally, LPG has four distinct domains: (i) a well conserved GPI anchor composed of 1-O-alkyl-2lyso-phosphatydylinositol (PI); (ii) a core composed of $\operatorname{Gal}(\alpha 1-6) \mathrm{Gal}(\alpha 1-3) \mathrm{Gal}_{f}(\beta 1-3)\left[\mathrm{Glc}(\alpha 1) \mathrm{PO}_{4}\right] \mathrm{Man}(\alpha 1-$ 3) Man $(\alpha 1-4)-\operatorname{GlcN}(\alpha-1)$ heptasaccharide; (iii) a portion of disaccharide repeats of the $\operatorname{Gal}(\beta 1-4)$ Man $(\alpha 1) \mathrm{PO}_{4}$ units and (iv) a terminal neutral oligosaccharide ("cap") [11]. In L. infantum, the repeat units of LPG display the addition of $\beta$ Glc to the C3 carbon in the Gal residues [23]. These side chain substitutions can vary between different strains of $L$. infantum which can have three different sets of side chains: Type I which has no side chain substitutions; Type II which has only one $\beta$ Glc addition to the Gal residue of the repeat units and Type III which contains two or three $\beta$ Glc residue substitutions on the Gal residue [21] (Figure 1). Interestingly, in the metacyclic promastigote form of LPG in this species there are no sugar substitutions in the repeat unit backbone [23]. Elucidation of the L. braziliensis LPG structure showed that procyclic promastigote forms are devoid of side-chains, whereas metacyclic LPG displays up to two $\beta$ Glc residues linked to the Gal residue of the repeat unit backbone [24]. It is not known to what extent interspecies variations in
New World species of Leishmania can differentially activate the host's immune system. Recently, the structural composition of L. braziliensis and L. infantum GIPLs revealed that the former are galactose rich and its structure is suggestive for the predominance of type II GIPLs having a Mano1-3 substitution to the proximal mannose and are mainly galactose terminating structures. On the other hand, L. infantum GIPLs are mainly of type I and/

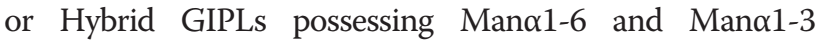
[Mano6] substitutions to the proximal mannose, respectively [22,25]. Those variations were implicated in a higher inhibitory activity in NO and cytokine production by L. braziliensis GIPLs compared to L. infantum. However, the role of LPGs from those species in this process has not been investigated.

This work is part of a wider study on the glycobiology of New World species of Leishmania. In previous studies, we reported on the LPG and GIPLs biochemical structures of L. braziliensis and L. infantum [22-24] and showed that the differences in GIPLs structures were relevant in the parasite biology [22]. In this study, we expanded those findings and show that the LPG of these two New World Leishmania species also differentially modulated the activation of mouse peritoneal macrophages.

\section{Methods}

\section{Ethics statement}

All animals were handled in strict accordance with animal practice as defined by the Internal Ethics Committee in

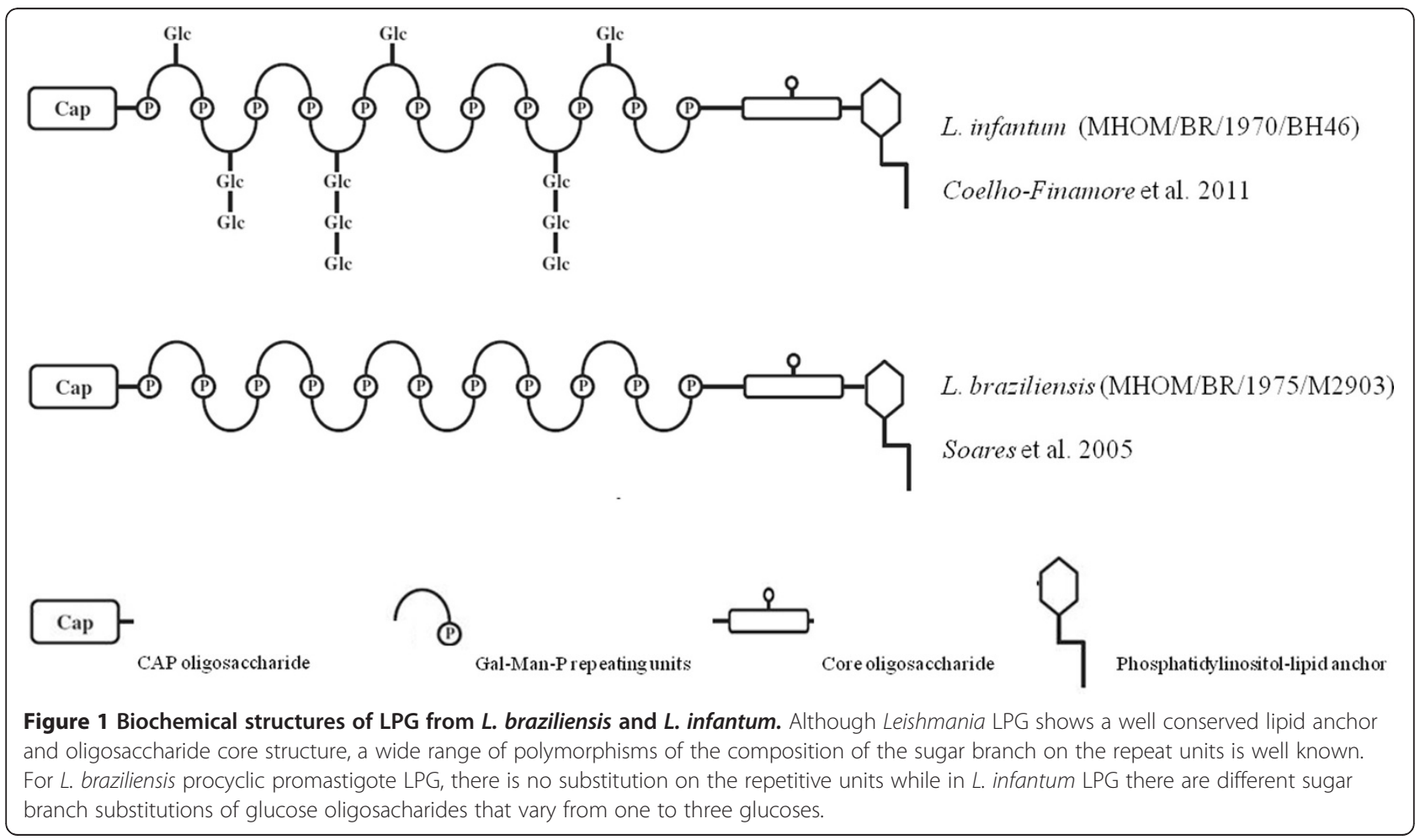


Animal Experimentation (CEUA) of Fundação Oswaldo Cruz (FIOCRUZ), Belo Horizonte (BH), Minas Gerais (MG), Brazil (Protocol P-0297-06). Knock-out mice handling protocol was approved by the National Commission of Biosafety (CTNBio) (protocol \#01200.006193/2001-16).

\section{Parasites}

World Health Organization Reference strains of $L$. braziliensis (MHOM/BR/1975/M2903) and L. infantum (MHOM/BR/1970/BH46) were used. Promastigotes were cultured in M199 medium supplemented with 10\% heatinactivated fetal bovine serum (FBS), penicillin 100 units/ $\mathrm{ml}$, streptomycin $50 \mu \mathrm{g} / \mathrm{ml}, 12.5 \mathrm{mM}$ glutamine, $0.1 \mathrm{M}$ adenine, $0.0005 \%$ hemin, and $40 \mathrm{mM}$ Hepes, $\mathrm{pH} 7.4$ at $26^{\circ} \mathrm{C}$ [23] until late log phase.

\section{Extraction and purification of LPG}

For optimal LPG extraction, late log phase cells were harvested and washed twice with PBS prior to extraction of LPG. The LPG extraction was performed as described elsewhere with solvent $\mathrm{E}\left(\mathrm{H}_{2} \mathrm{O} /\right.$ ethanol/diethylether/pyridine/ $\left.\mathrm{NH}_{4} \mathrm{OH} ; 15: 15: 5: 1: 0.017\right)$ after a sequential organic solvent extraction [26]. For purification, the solvent E extract was dried under $\mathrm{N}_{2}$ evaporation, resuspendend in $2 \mathrm{ml}$ of $0.1 \mathrm{~N}$ acetic acid/0.1 M NaCl, and applied onto a column with $2 \mathrm{ml}$ of phenyl-Sepharose, equilibrated in the same buffer. The column was washed with $6 \mathrm{ml}$ of $0.1 \mathrm{~N}$ acetic acid/ $0.1 \mathrm{M} \mathrm{NaCl}$, then $1 \mathrm{ml}$ of $0.1 \mathrm{~N}$ acetic acid and finally $1 \mathrm{ml}$ of endotoxin free water. The LPG was eluted with $4 \mathrm{ml}$ of solvent $\mathrm{E}$ then dried under $\mathrm{N}_{2}$ evaporation. LPG concentration was determined as described elsewhere [27]. Prior to use on in vitro macrophage cultures, LPG was diluted in fresh RPMI. All solutions were prepared in sterile, LPS-free distilled water (Sanobiol, Campinas, Brazil).

\section{Purification of murine peritoneal macrophages and cell culture}

Thioglycollate-elicited peritoneal macrophages were extracted from BALB/c, C57BL/6 and C57BL/6 (TLR2 ${ }^{-/-}$ and $\mathrm{TLR}^{-/-}$knockouts) by peritoneal washing with ice cold serum-free RPMI and enriched by plastic adherence for $1 \mathrm{~h}$ at $37^{\circ} \mathrm{C} / 5 \% \mathrm{CO}_{2}$. Cells $\left(3 \times 10^{5}\right.$ cells/well $)$ were washed with fresh RPMI then cultured in RPMI, $2 \mathrm{mM}$ glutamine, $50 \mathrm{U} / \mathrm{ml}$ of penicillin and $50 \mu \mathrm{g} / \mathrm{mL}$ streptomycin supplemented with $10 \%$ FBS in 96-well culture plates $\left(37^{\circ} \mathrm{C} / 5 \% \mathrm{CO}_{2}\right)$. Cells were primed with gamma interferon $(\mathrm{IFN}-\gamma)(3 \mathrm{IU} / \mathrm{mL})$ [28] for $18 \mathrm{~h}$ prior to incubation with LPG or live stationary Leishmania parasites (10:1), LPG $(10 \mu \mathrm{g} / \mathrm{mL})$ or lipopolysaccharide (LPS) (100 ng/mL).

\section{Chinese Hamster Ovary (CHO) cell lines}

The CHO reporter cell lines (TLR2-TLR4-, which do not express TLR2 nor TLR4; TLR2+, expressing TLR2; TLR4+, expressing TLR4 [29] were maintained as adherent mono- layers in Ham's F-12/DMEM supplemented with 5\% FBS, at $37^{\circ} \mathrm{C}, 5 \% \mathrm{CO}_{2}$, and antibiotics. All of the cell lines are derived from clone $3 \mathrm{E} 10$, that has been stably transfected with a reporter construct containing the structural gene for CD25 under the control of the human E-selectin promoter. This promoter contains a NF-kB binding site; CD25 surface expression is completely dependent upon NF-kB translocation to the cell nucleus [30].

\section{Cytokine and nitrite measurements}

For CBA multiplex cytokine detection, cells were plated, primed as described above and incubated for $18 \mathrm{~h}\left(37^{\circ} \mathrm{C}\right.$, $\left.5 \% \mathrm{CO}_{2}\right)$. LPG $(10 \mu \mathrm{g} / \mathrm{mL})$ and live stationary promastigotes (10:1 ratio) were added and incubated for $48 \mathrm{~h}$, LPS (100 ng/mL) was added as a positive control. For negative controls fresh medium was added. Supernatants were collected and cytokines (IL1- $\beta$, IL-2, IL-4, IL-5, IL-6, IL-10, IL-12p40, IFN- $\gamma$ and TNF- $\alpha$ ) were determined using the BD CBA Mouse Cytokine assay kits according to the manufacturer's specifications (BD Biosciences, CA, USA). Flow cytometry measurements were performed on a FACS Calibur flow cytometer (Becton Dickinson, Mountain View, CA). Cell-Quest ${ }^{\text {TM }}$ software package provided by the manufacturer was used for data acquisition and the FlowJo software 7.6.4 (Tree Star Inc., Ashland, OR, USA) was used for data analysis. A total of 1,800 events were acquired for each preparation [22]. Results are representative of two experiments in duplicate. Nitrite concentrations were determined by Griess reaction [31].

For the inhibition assay, purified cells were primed for $6 \mathrm{~h}$ with $3 \mathrm{IU} / \mathrm{ml}$ of IFN- $\gamma$ prior to stimulation with LPG $(10 \mu \mathrm{g} / \mathrm{ml})$. Cells were incubated for $18 \mathrm{~h}$ at $37^{\circ} \mathrm{C} / 5 \%$ $\mathrm{CO}_{2}$, then LPS $(100 \mathrm{ng} / \mathrm{ml})$ was added to the medium and incubated for another $24 \mathrm{~h}$ at $37^{\circ} \mathrm{C} / 5 \% \mathrm{CO}_{2}$. Supernatants were collected and nitrite concentrations determined by Griess reaction. Results shown are the mean of two experiments in triplicate [22].

\section{Flow cytometry analysis}

In order to evaluate the activation of NFKB by LPG, $\mathrm{CHO}$ reporter cells were plated at a density of $1 \times 10^{5}$ cells/well in 24-well tissue culture dishes. The following day, either molecule or bacteria (Staphylococcus aureus [1000 bacteria/well], positive control of TLR2; LPS (200 ng/ well), positive control of TLR4; or LPG $(0.2 \mu \mathrm{g}$ or $0.02 \mu \mathrm{g} /$ well) from $L$. braziliensis or from $L$. infantum was added as indicated, for $18 \mathrm{~h}$. The cells were harvested with trypsinEDTA, washed with medium and with PBS. Subsequently, the cells were counted and $1 \times 10^{5}$ were cells stained with PE-labeled anti-CD25 (mouse mAb to human CD25, R-PE conjugate; Caltag Laboratories, Burlingame, CA) 1:200 in PBS, on ice, in the dark, for $30 \mathrm{~min}$. After labeling, the cells were washed twice with same buffer, resuspended in $1 \mathrm{mM}$ sodium azide in PBS, and examined by flow cytometry 
(BD Biosciences, San Jose, CA) for the expression of surface $\mathrm{CD} 25$ as described [29]. Analyses were performed using CellQuest software (BD Biosciences).

\section{Preparation of cell lysates and immunoblotting}

Thioglycollate-elicited peritoneal macrophages were plated as above on 6 well tissue culture plates $\left(3 \times 10^{6} /\right.$ well $)$ for $18 \mathrm{~h}$ prior to assay. The cells were washed with warm RPMI and incubated with LPG from both species for different times $(5,15,30$ and $45 \mathrm{~min})$ or with medium (negative control) or LPS (100 ng/ml) as positive control. Cells were then washed with ice-cold PBS and lysed in lysis buffer $(20 \mathrm{mM}$ Tris-HCl pH 7.5, 1\% Triton $\times-100,1 \mathrm{mM}$ sodium orthovanadate, $1 \mathrm{mM}$ phenylmethylsulfonyl fluoride (PMSF), $50 \mathrm{mM}$ sodium fluoride, $150 \mathrm{mM} \mathrm{NaCl}, 5 \mathrm{mM}$ ethylenediamine tetraacetic acid (EDTA), 10\% glycerol (v/v), $0.5 \mathrm{mM}$ dithiothreitol (DTT) and protease inhibitor cocktail from Sigma $\left.{ }^{\circledR}\right)$. Cells were harvested with a plastic scraper and centrifuged at $13,000 \times g\left(4^{\circ} \mathrm{C}, 10 \mathrm{~min}\right)$. Supernatants were transferred to new tubes and stored at $-20^{\circ} \mathrm{C}$ until used for immunoblotting. Cell lysates were resolved by SDS-PAGE, transferred to a nitrocellulose membrane and blocked (5\% milk in TBS-0.1\% Tween 20) for $1 \mathrm{~h}$. Primary Abs (anti-dually phosphorylated ERK, dually phosphorylated p38 and -Total ERK, 1:1,000, total p38 primary antibody was used as a normalizer) were incubated for $16 \mathrm{~h}$ at $4^{\circ} \mathrm{C}$. Membranes were washed $(3 \times$ $10 \mathrm{~min}$ ) with TBS-0.1\% Tween 20 and incubated $1 \mathrm{~h}$ with anti-mouse IgG conjugated with peroxidase $(1: 10,000)$. The reaction was visualized using luminol [22].

\section{Statistical analyses}

For nitrite and cytokine measurements, the ShapiroWilk test was conducted to test the null hypothesis that data were sampled from a Gaussian distribution [32]. The $\mathrm{P}$ value $(\mathrm{P}>0.05)$ showed that data did not deviate from Gaussian distribution. For this reason, Student's " $t$ " test and ANOVA were performed to test equality of population medians among groups and independent samples. Data were analyzed using GraphPad Prism 5.0 software (Graph Prism Inc., San Diego, CA) and P $<0.05$ was considered significant.

\section{Results}

\section{Nitrite and cytokine production}

In order to evaluate the role of TLR2 and TLR4 in this process, IFN- $\gamma$ primed peritoneal macrophages from $\mathrm{BALB} / \mathrm{c}, \mathrm{C} 57 \mathrm{BL} / 6, \mathrm{TLR}^{-/-}$and $\mathrm{TLR} 4^{-/-}$mice were incubated with $10 \mu \mathrm{g} / \mathrm{ml}$ of LPG and live promastigotes (10:1) from $L$. braziliensis and L. infantum. Nitrite and cytokine concentrations determined on the supernatants after $48 \mathrm{~h}$ (Figures 2, 3 and 4) [22].

A higher NO production was detected on IFN- $\gamma$-primed C57BL/6 macrophages stimulated with both LPGs and live promastigotes when compared to macrophages from BALB/c mice $(\mathrm{P}<0.001)$ (Figure $2 \mathrm{~A})$. There was a significant decrease in $\mathrm{NO}$ production in IFN- $\gamma$-primed $\mathrm{TLR}^{-/-}$macrophages stimulated with LPG in comparison to $\mathrm{TLR}^{-/-}$and wild type $\mathrm{C} 5 \mathrm{BL} / 6$ macrophages $(\mathrm{P}<0.01)$ suggesting the involvement of TLR4 in this activation. No significant difference of NO production was noticed in macrophages from TLR2 ${ }^{-/-}$or TLR4 ${ }^{-/-}$mice stimulated with live promastigotes when compared to wild type C57BL/6 $(\mathrm{P}<0.05)$ (Figure 2A).

In a multiplex flow cytometer approach, the concentrations of several cytokines were determined on the same supernatants used for nitrite measurement. No significant quantities of IL-2, IL-4, IL-5 and IFN- $\gamma$ were detected (data not shown); on the other hand, a significant production of TNF- $\alpha$, IL- $1 \beta$ and IL- 6 was observed (Figure $3 \mathrm{~B}$ and $4 \mathrm{~A}$ and $\mathrm{B}$ ). As for nitrite production, these cytokines production, in $\mathrm{BALB} / \mathrm{c}$ and $\mathrm{C} 57 \mathrm{BL} / 6$ macrophages, were higher for L. braziliensis LPG stimulated cells $(\mathrm{P}<0.05)$. In all experiments, live parasites from both species induced cytokine production close to background levels (Figure $3 \mathrm{~B}$ and $4 \mathrm{~A}$ and $\mathrm{B}$ ). As expected, LPG was able to induce these three cytokines in wild type and $\mathrm{TLR}^{-/-}$mice but not in $\mathrm{TLR} 4^{-/-}$mice. A reduction in the production of these cytokines in $\mathrm{TLR}^{-/-}$macrophages was demonstrated, indicating the importance of this receptor in LPG recognition and signaling. A complete abrogation of the production of these cytokines was observed in TLR4 ${ }^{-/-}$mice suggesting also the participation of TLR4 in LPG recognition and signaling. There was no significant production of IL-10, IL12 p40 (Figure 2) or IFN- $\gamma$, IL-2, IL-4 and IL-5 after LPG or live promastigote incubation in any of the mouse strains tested (data not shown).

\section{Activation of MAPKs}

To better access the signaling events around LPG recognition and macrophage activation, BALB/c macrophages were incubated with $L$. braziliensis and L. infantum LPG and MAPK activation was assessed as a function of time. A strong ERK and JNK activation was observed in L. braziliensis in LPG stimulated macrophages after $15 \mathrm{~min}$ incubation but no activation was detected before or after this time interval. In contrast, no ERK activation by L. infantum LPG was found. L. braziliensis LPG stimulated a sharp p38 and ERK phosphorylation beginning in 5 minutes and peaking at 15 minutes (Figure 5). In a different activation profile, a progressive increase of p38 and JNK was observed for L. infantum LPG stimulated macrophages (Figure 5). Together, these data suggests that the LPG from these two species differentially activates MAPK, which may account for the differences in macrophage nitrite and cytokine production and maybe the reason for differential pathogenesis caused by these two species. 

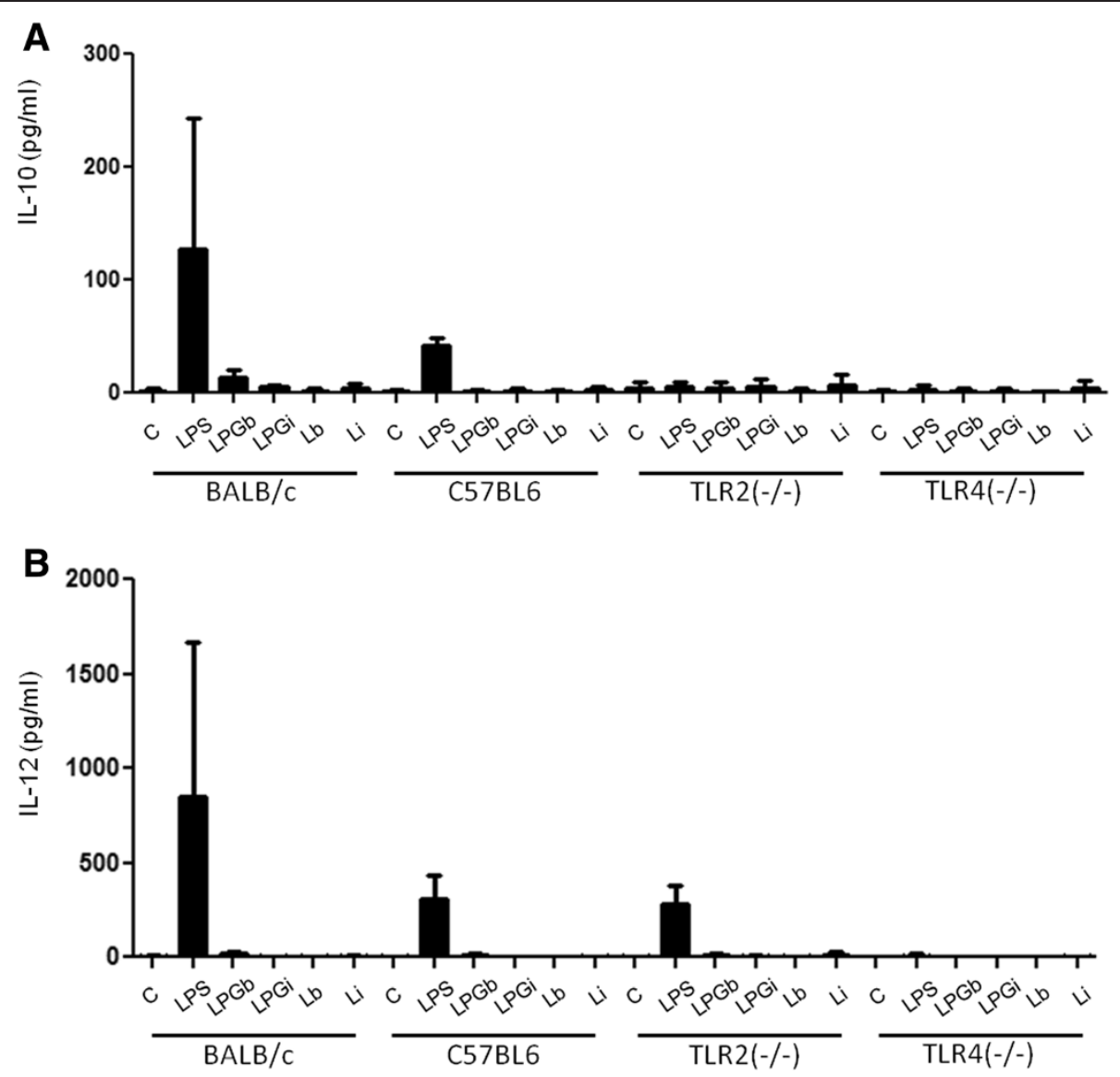

Figure 2 IL-10 (A) and IL-12 (B) production by IFN- $\gamma$ primed macrophages stimulated with LPG and live parasites. C, negative control; LPGb, L. braziliensis LPG; LPGi, L. infantum LPG; Lb, L. braziliensis live promastigotes and Li, L. infantum live promastigotes. Cells were pre-incubated with IFN-y (3 IU/ml) for $18 \mathrm{~h}$ then $10 \mathrm{\mu g} / \mathrm{mL}$ of LPG. As a positive control, LPS (100 ng/mL) was added. Fresh medium alone was added to negative control cells. Supernatants were collected 48 hours later, cytokine concentrations determined by flow cytometry. ANOVA test was performed and $P<0.05$ was considered significant.

LPGs from Leishmania infantum and from Leishmania brasiliensis are agonists of TLR2, inducing ex vivo the nuclear translocation of NFkB

In order to better assess the role of TLR2 and TLR4 in the recognition of LPG, the activation of NFkB was performed. $\mathrm{CHO}$ reporter cells were treated with LPG for $18 \mathrm{~h}$ and reporter protein CD25 expression evaluated by flow cytometry. As showed in Figure 6, after exposure of $\mathrm{CHO}$ cells expressing TLR2 (TLR2+) to $0.2 \mu \mathrm{g}$ or to $0.02 \mu \mathrm{g}$ of LPGb, there was a higher production of CD25 protein, resulting from expression of the gene reporter, in comparison with the CHO cells without that exposition, meaning that LPGb is a stark agonist of TLR2, inducing the nuclear translocation of NFkB. After the exposition of TLR4+ cells to LPGb or of TLR4+ or TLR2+ to LPGi, there was a slightly higher production of the protein codified by the gene reporter than the production in the nonstimulated cells, meaning that the LPGb and LPGi are weak agonists of TLR4 and that LPGi is a weak agonist of TLR2.
Inhibition of nitrite production in BALB/c macrophages by Leishmania LPG

Previously, it was shown that GIPLs from both species were able to inhibit NO production in LPS stimulated mice peritoneal macrophages [22]. To determine whether LPG would also result in inhibitory activity, BALB/c macrophages were incubated in the presence of LPG for $18 \mathrm{~h}$ prior to LPS exposure. A strong inhibition of NO production stimulated by LPS was observed after LPG incubation from both species. The inhibition was over $70 \%(\mathrm{P}<0.01)$ for LPG from both species (Figure 7).

\section{Discussion}

Leishmaniasis is considered by the World Health Organization as one of the six major infectious diseases in the whole world [33] and affects over 1.5 million people every year worldwide. In Brazil, the majority of visceral and tegumentary cases are due to $L$. infantum and L. braziliensis, respectively. Parasite glycoconjugates have 

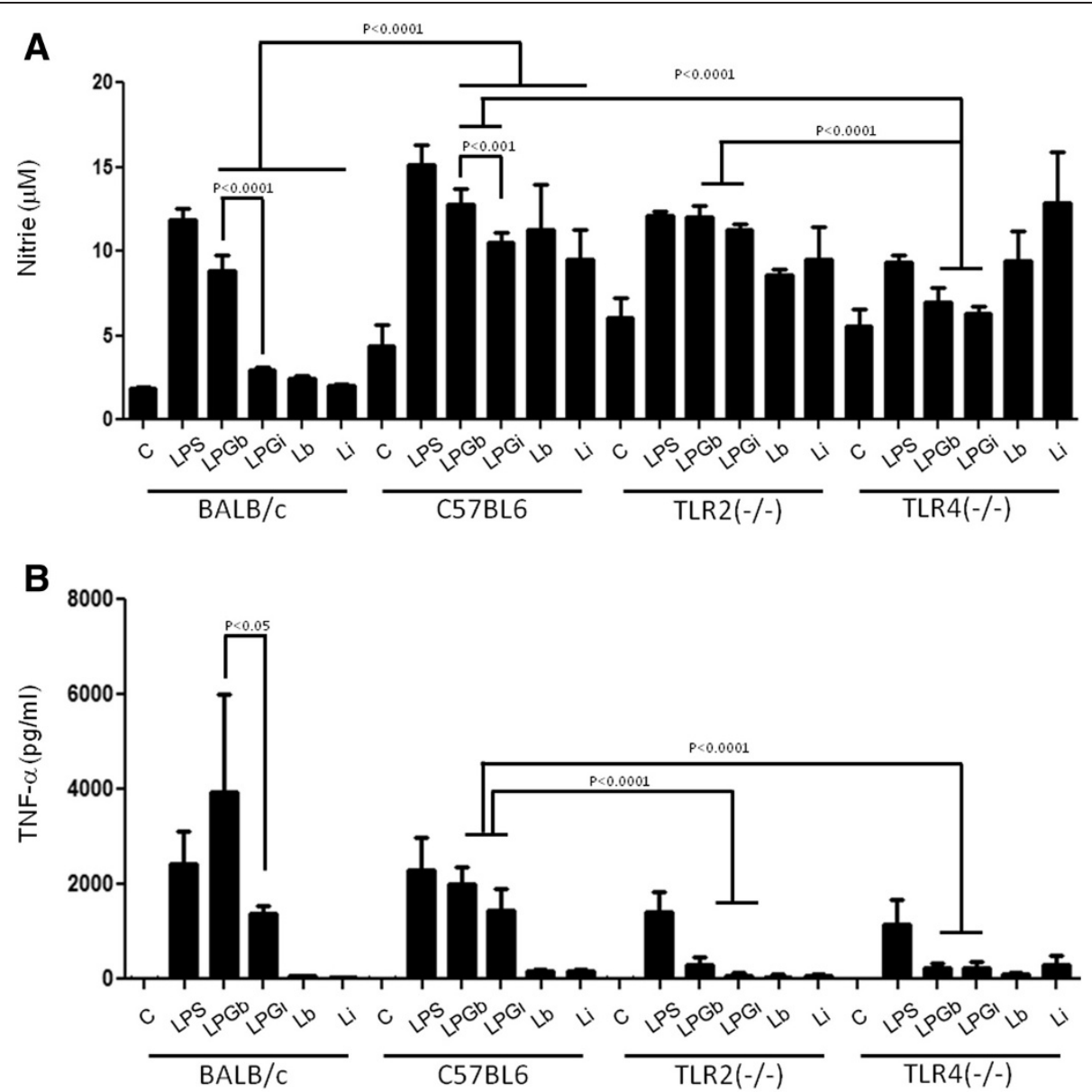

Figure 3 Nitrite (A) and TNF-a (B) production by IFN- $p$ primed macrophages stimulated with LPG and live parasites. C, negative control; LPGb, L. braziliensis LPG; LPGi, L. infantum LPG; Lb, L. braziliensis live promastigotes and Li, L. infantum live promastigotes. Cells were pre-incubated with IFN- $\gamma(3 \mathrm{IU} / \mathrm{ml}$ ) for $18 \mathrm{~h}$ then $10 \mathrm{\mu g} / \mathrm{mL}$ of LPG. As a positive control, LPS (100 ng/mL) was added. Fresh medium alone was added to negative control cells. Supernatants were collected 48 hours later. Nitrite concentration was measured by Griess reaction and cytokine concentrations were determined by flow cytometry. ANOVA test was performed and $\mathrm{P}<0.05$ was considered significant.

long being incriminated in a variety of events during parasite-host interactions modulating important host cell functions [11,22,34,35]. Among these glycoconjugates, LPG is the best studied especially in Old World species of Leishmania. In this study, the role of the LPGs, from two epidemiologic important Leishmania species in Brazil, in interfering in signaling mechanisms was assessed in murine macrophages.

Since it has been reported that there is no significant difference between procyclic and metacyclic $L$. major LPG NK cell activation [36] and that the conserved GPI anchor is important for LPG activity [32] this work used stationary phase LPG. Although metacyclic promastigotes can be readily prepared from culture by several methods, only a small percentage of parasites, less than $5 \%$ [37], differentiate into these forms. For this reason, all experiments described here could not have been done with metacyclic LPG.
One of the most important events in the initial steps of Leishmania infection is the production of $\mathrm{NO}$ by macrophages. In many models, its production is dependent on a combination of IFN- $\gamma$ and TNF- $\alpha$ via TLR-dependent mechanisms [38]. Our results indicated that LPG from both species could induce the production of $\mathrm{NO}$ in IFN- $\gamma$-primed macrophages. Its production was higher in macrophages stimulated with L. braziliensis LPG than that of L. infantum. C57BL/6 macrophages incubated with both LPGs showed a higher production of NO, IL-1 $\beta$ and IL-6 than BALB/c. On the other hand, TNF- $\alpha$ production after stimulation by L. braziliensis LPG was higher in BALB/c macrophages (Figures 2, 3, 4). Similar results were also observed for GIPLs [22], these differences of activation between $\mathrm{C} 57 \mathrm{BL} / 6$ and $\mathrm{BALB} / \mathrm{C}$ mice may be due to the genetic background of mouse strains $[37,39]$. In the present study, no macrophage activation 

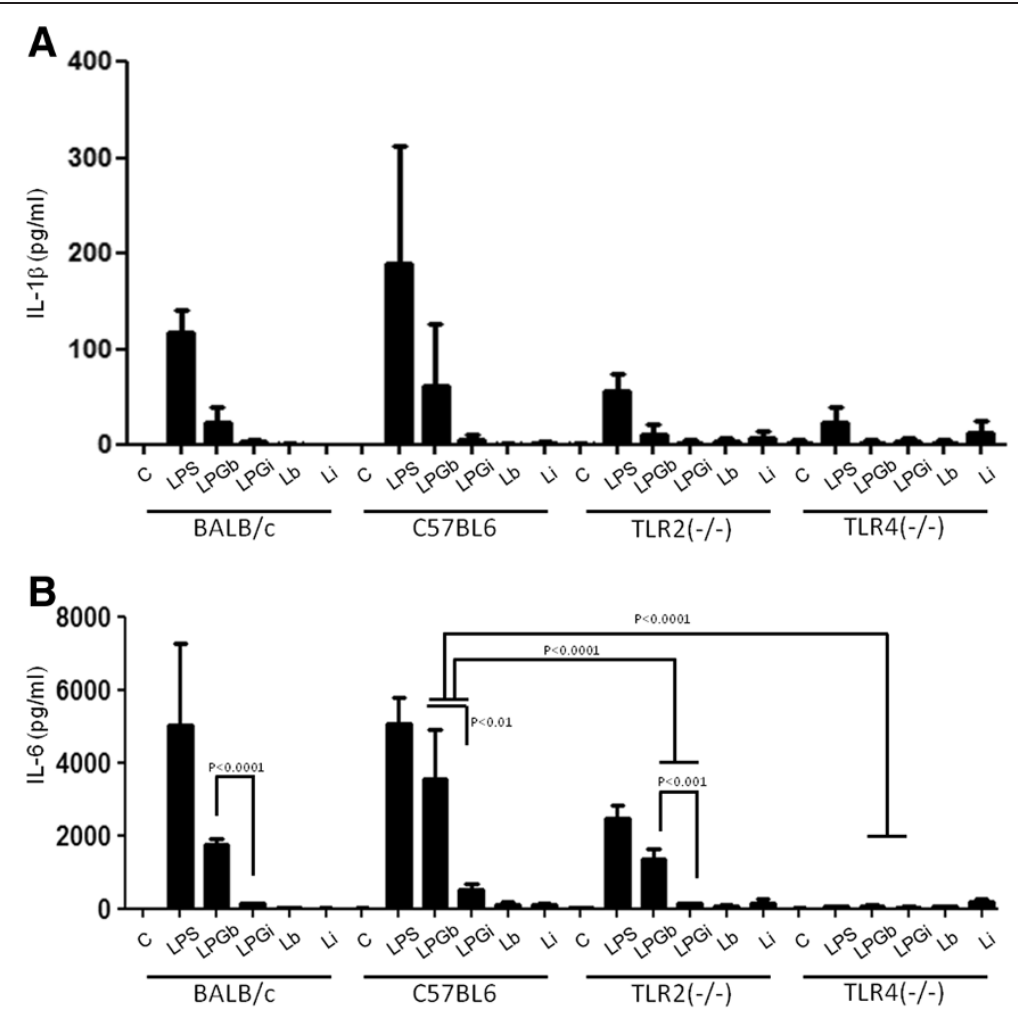

Figure 4 IL-1 $\beta$ (A) and IL-6 (B) production by IFN- $\gamma$ primed macrophages stimulated with LPG and live parasites. C, negative control; LPGb, L. braziliensis LPG; LPGi, L. infantum LPG; Lb, L. braziliensis live promastigotes and Li, L. infantum live promastigotes. Cells were pre-incubated with IFN- $\gamma(3 \mathrm{IU} / \mathrm{ml})$ for $18 \mathrm{~h}$ then $10 \mathrm{\mu g} / \mathrm{mL}$ of LPG. As a positive control, LPS (100 ng/mL) was added. Fresh medium alone was added to negative control cells. Supernatants were collected 48 hours later, cytokine concentrations were determined by flow cytometry. ANOVA test was performed and $\mathrm{P}<0.05$ was considered significant.

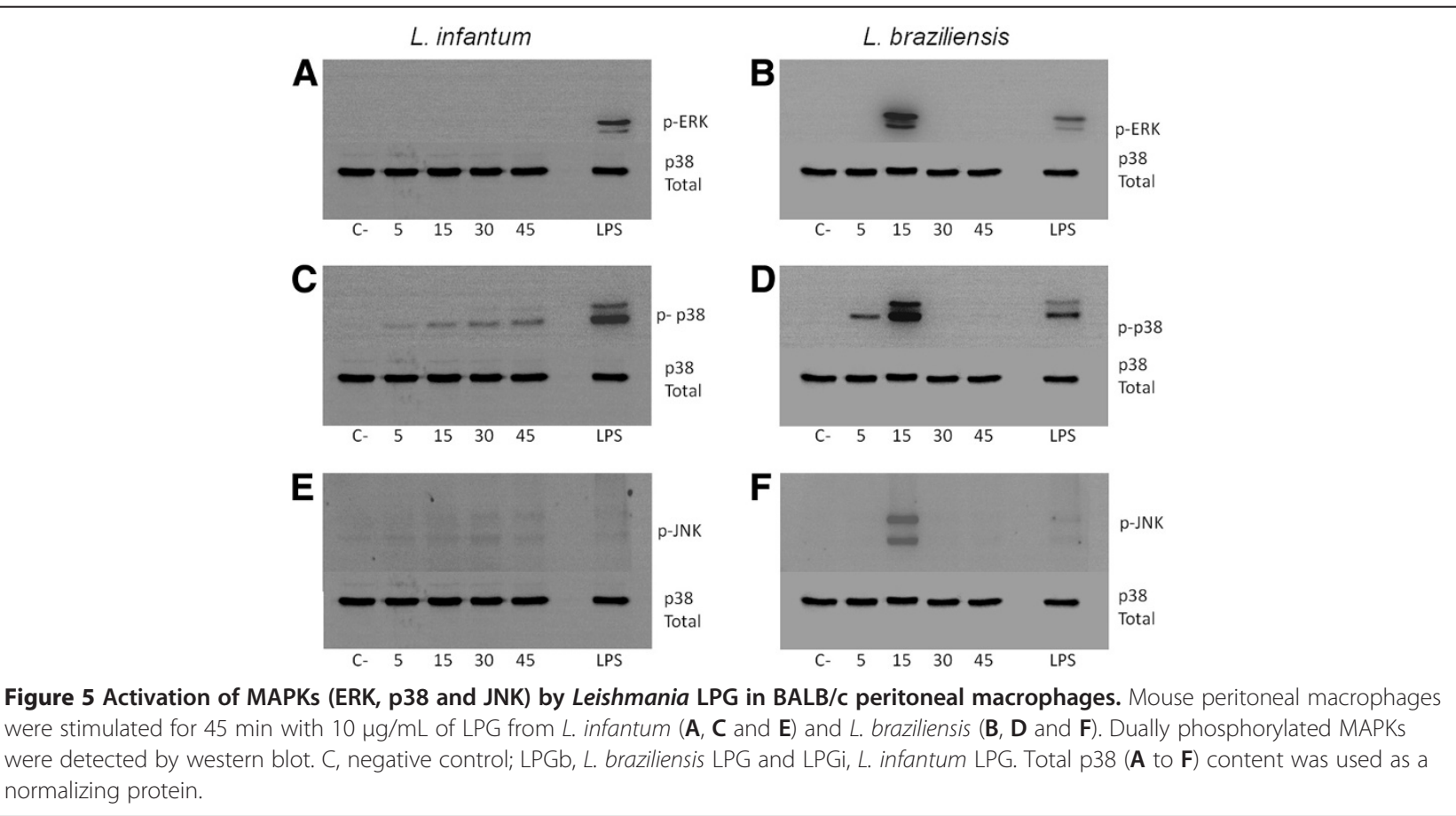




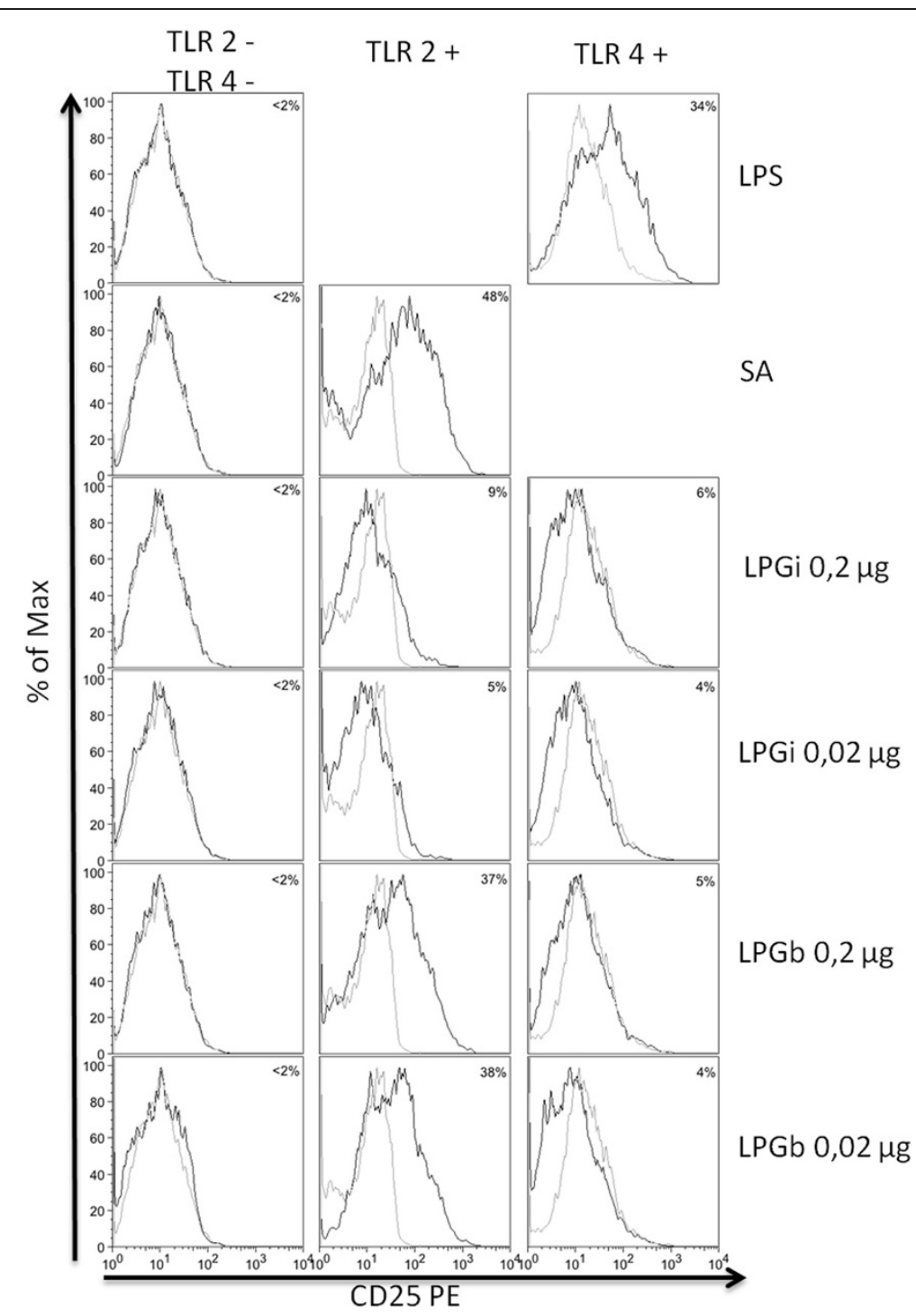

Figure 6 LPGs purified from Leishmania infantum and Leishmania braziliensis induce translocation of NFkB through TLRs. CHO cells expressing TLR2 (TLR2+), TLR4 (TLR4+), or neither (TLR2-/TLR4-) were either untreated (gray line) or exposed (black line) to LPS, Staphylococcus aureus $(\mathrm{SA})$, L. infantum LPG (LPGi) or L. braziliensis LPG (LPGb), as indicated. CD25 expression was measured by flow cytometry $18 \mathrm{~h}$ after stimulation. Percentage $=$ percentage of CD25 expression on stimulated cells minus percentage of CD25 expression on non-stimulated cells.

was observed in WT, TLR2 ${ }^{-1-}$ and $\mathrm{TLR}^{-1-}$ murine cells after incubation with live promastigotes.

Previous reports have shown that in vivo, proinflammatory cytokines such as IL- $1 \beta$, IL- 6 and TNF- $\alpha$, as well as chemokines, are induced in the initial events of $L$. major and $L$. donovani, causative agents of cutaneous and visceral leishmaniasis infection in the Old World, respectively. Similar results were observed here using L. braziliensis and L. infantum LPGs since macrophages stimulated with L. braziliensis LPG exhibited higher cytokine and NO production compared to that of the visceral form $L$. infantum (Figures 2 and 3). This finding was confirmed after incubation of the LPGs with
CHO cells demonstrating that $L$. braziliensis LPG was able to induce NF-kB translocation. These data reflect a similar stimulation pattern between Old World and New World species that causes similar disease outcomes. More importantly, the lack of IL-10, IL-12 production, persistent MAPKs activation and the lack of NF-kB translocation via TLR4 ensure that no traces of endotoxins were present in our preparations.

Because most Leishmania glycoconjugates are on the external surface of the cell plasma membrane or secreted, they are able to modulate important functions in cell biology [22]. The interspecies variations observed in L. infantum and L. braziliensis may be dependent on the 


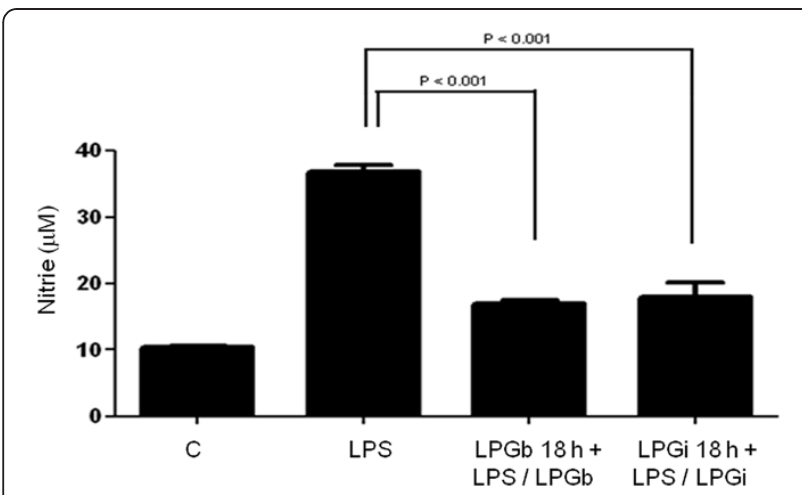

Figure 7 Modulation of nitrite by Leishmania LPG in BALB/C macrophages. Cells were incubated with $L P G(10 \mu \mathrm{g} / \mathrm{ml})$ from $L$. braziliensis (LPGb) or L. infantum (LPGi) for $18 \mathrm{~h}$ prior to stimulation with LPS $(100 \mathrm{ng} / \mathrm{ml})$ combined with $10 \mu \mathrm{g} / \mathrm{ml}$ of LPG. Cells where then incubated for another $24 \mathrm{~h}$ and nitrite content was measured on the supernatants by Griess reaction.

action and specificity of glycosyltransferases [23,24]. For example, in L. donovani (MONGI strain) critical glycosyltransferases are down regulated in the metacyclic phase [40]. Such intra and interspecies variability is likely to have implications in antigenicity enabling carbohydrates to be important sources of biological diversity [36]. In this work, the differential pattern of macrophage activation might be due to carbohydrate polymorphisms in the LPG of these two species. Our results with the two New World species of Leishmania are consistent with the reports from many Old World Leishmania species and strains which showed that LPG with its varied structural polymorphisms induced different levels of NO and TNF- $\alpha$ in murine macrophages $[20,21,34]$.

No IFN-gamma, IL-10 or IL-12 production was observed by cells stimulated with LPGs from both New World species. Similar observations can be made in the human visceral leishmaniasis where immune suppression and a mixed Th1/Th2 profile modulate most of the immune response [33]. The lack of IL-12 production by cells stimulated with Leishmania GPI-anchored glycoconjugates was also observed elsewhere, where mouse peritoneal macrophages failed to produce IL-12 when co-incubated with $L$. braziliensis or L. infantum GIPLs and when also stimulated with IFN- $\gamma$ or LPS [41]. It is also important to note that the lack of IL-12 production was not due to IL-10 release, since we did not observe any production of this cytokine (Figure 2A). This is similar to that observed when macrophages were treated with synthetic $L$. major LPG [7] and $L$. braziliensis and L. infantum GIPLs [22].

In the present work we also evaluated the role of TLRs on the recognition and signaling of LPG. TLR2 was first incriminated as the LPG receptor in macrophages and NK cells [34,42]. Additional in vivo experiments demonstrated the importance of TLR3, TLR4 and TLR9 in different Leishmania species [43]. By using RNA interference methodologies, it was shown that both TLR2 and TLR3 were implicated in the recognition of $L$. donovani LPG in IFN- $\gamma$ primed macrophages [44]. In vivo, it was shown that TLR4 deficient mice are more susceptible to Leishmania infection, failing to efficiently resolve the lesions [45] while TLR2 shows a more regulatory role in $L$. braziliensis-infected dendritic cells [41]. Here, we demonstrated in vitro with macrophages and $\mathrm{CHO}$ cells that TLR2 and, to a lesser extent, TLR4 were recognized by LPGs from both species clearly suggesting their participation in the LPG signalling. The inability of $L$. infantum LPG to activate NF-kB and ERK could be suggested as an evasion mechanism compared to L. braziliensis LPG.

Given that the LPGs were able to induce NO and cytokine production, we investigated whether activation of MAPK signalling was affected. In contrast to GIPLs (which fail to activate MAPKs) [22], LPG from both species activated MAPKs, but with different kinetics. $L$. infantum LPG was not able to activate ERK1/2. In contrast, $L$. braziliensis LPG strongly activated MAPK activity after 15 min. Interestingly, p38 and JNK activation exhibited a gradual and transient profile in $L$. infantum and $L$. braziliensis, respectively (Figure 5). Although a punctual MAPK activation was observed for L. braziliensis LPG after $5 \mathrm{~min}$, this may not be a sufficient stimulus for IL-12 production. Activation of p38 appears to be important for controlling Leishmania infection since anisomycin reduced parasite survival upon p38 activation [46]. Feng et al. [7] reported that ERK1/2 and p38 are important for NO and TNF- $\alpha$ production by macrophages stimulated with LPS. Consistent with those observations, our data suggests that the LPGs from New World species are also able to differentially activate MAPKs.

The data presented here demonstrated a differential production of NO, cytokines and MAPK activation profile by $L$. braziliensis and $L$. infantum LPG stimulated macrophages. The LPG from these species have a limited proinflammatory potential since they fail to activate important proinflammatory cytokines such as IL-12 and only activate low amounts of IL- $1 \beta$ while inducing activation of early inflammatory cytokines such as TNF- $\alpha$ and IL-6. Additionally, as seen in Figure 7, preincubation with LPG prior to stimulation with LPS reduced the nitrite production to basal levels, indicating that the dynamics of infection must be well regulated and consistent with the long-known proposal that LPG acts as a multifunctional virulence factor for Leishmania.

\section{Conclusion}

Together with the complex interface of interaction between parasite and host, glycoconjugate interspecies polymorphisms, not only in the LPG, but also in GIPLs, gp63 and other GPI-anchored molecules, are important 
for differential regulation of initial events of the immune response as well as establishment of infection. Our results with New World species are consistent with this issue of the importance of LPG polymorphisms; structural variations in LPG resulted in differential activation of macrophages (NO, cytokines and MAPKs). Those polymorphisms could result in different clinical outcomes, such as those shown by $L$. infantum and $L$. braziliensis, causative agents of visceral and tegumentary forms, respectively [47].

\section{Competing interests}

The authors declare that they have no competing interests.

\section{Authors' contributions}

Conceived and designed the experiments: ICl, RRA, RPS, MNM, MAC, SJT; performed the experiments: ICI, RRA, NLM, MAC; analyzed the data: ICl, RRA, MAC, RPPS; helped to draft the manuscript: ICI, RRA, MNM, MAC, NLM, SJT, RPS. All authors read and approved the final manuscript.

\section{Acknowledgements}

I. C. Ibraim and R. R. Assis have contributed equally for the manuscript. We thank Douglas T. Golenbock (University of Massachusetts Medical School, Worcester, Mass.) for providing us with the $\mathrm{CHO}$ stably transfected cell lines and the Program for Technological Development in Tools for Health-PDTIS -FIOCRUZ for use of its facilities. R. P. Soares, M. N. Melo (\#305042/2010-6 and \#471465/2009-7) and M. A. Campos are research fellows supported by Conselho Nacional de Pesquisa e Desenvolvimento (CNPq). This work was supported by Tropical Diseases Research-World Health Organization (ID A50880), by the Fundação de Amparo à Pesquisa do Estado de Minas Gerais (FAPEMIG), by CNPq, by the Instituto Nacional de Ciência e Tecnologia de Vacinas/CNPq/FAPEMIG (INCTV/CNPq/FAPEMIG) and the Programa Estratégico de Pesquisa em Saúde VNI (PAPES)/FIOCRUZ/CNPq. R. R. Assis is supported by FAPEMIG. S. J. Turco is supported by National Institutes of Health (NIH), USA (Al31078). I. C. Ibraim is supported by Coordenação de Aperfeiçoamento de Pessoal de Nível Superior (CAPES). N. L. Pessoa is supported by CNPq.

\section{Author details}

${ }^{1}$ Centro de Pesquisas René Rachou, Fundação Oswaldo Cruz - FIOCRUZ, Av. Augusto de Lima, 1715, 30190-002, Belo Horizonte, Brazil. ²Departamento de Parasitologia, Universidade Federal de Minas Gerais, Belo Horizonte, MG, Brazil. 'Department of Biochemistry, University of Kentucky Medical Center, Lexington, KY, USA.

Received: 31 October 2012 Accepted: 19 February 2013 Published: 7 March 2013

\section{References}

1. Grimaldi $G \mathrm{Jr}$, Tesh RB, McMahon-Pratt D: A review of the geographic distribution and epidemiology of leishmaniasis in the New World. Am J Trop Med Hyg 1989, 41:687-725.

2. Herwaldt BL: Leishmaniasis. Lancet 1999, 354:1191-1199.

3. Evans TG, Thai L, Granger DL, Hibbs JB Jr: Effect of in vivo inhibition of nitric oxide production in murine leishmaniasis. J Immunol 1993, 151:907-915.

4. Gazzinelli RT, Ropert C, Campos MA: Role of the Toll/interleukin-1 receptor signaling pathway in host resistance and pathogenesis during infection with protozoan parasites. Immunol Rev 2004, 201:9-25.

5. Merida I, Pratt JC, Gaulton GN: Regulation of interleukin 2-dependent growth responses by glycosylphosphatidylinositol molecules. Proc Natl Acad Sci U S A 1990, 87:9421-9425.

6. Saltiel AR: The role of glycosyl-phosphoinositides in hormone action. J Bioenerg Biomembr 1991, 23:29-41.

7. Feng GJ, Goodridge HS, Harnett MM, Wei XQ, Nikolaev AV, Higson AP, Liew FY: Extracellular signal-related kinase (ERK) and p38 mitogen-activated protein (MAP) kinases differentially regulate the lipopolysaccharidemediated induction of inducible nitric oxide synthase and IL-12 in macrophages: Leishmania phosphoglycans subvert macrophage IL-12 production by targeting ERK MAP kinase. J Immunol 1999, 163:6403-6412.
8. Tachado SD, Gerold P, Schwarz R, Novakovic S, McConville M, Schofield L: Signal transduction in macrophages by glycosylphosphatidylinositols of Plasmodium, Trypanosoma, and Leishmania: activation of protein tyrosine kinases and protein kinase $C$ by inositolglycan and diacylglycerol moieties. Proc Natl Acad Sci U S A 1997, 94:4022-4027.

9. Soares RP, Torrecilhas AC, Assis RR, Rocha MN, Moura ECFA, Freitas GF, Murta SM, Santos SL, Marques AF, Almeida IC, Romanha AJ: Intraspecies variation in trypanosoma cruzi GPI-Mucins: biological activities and differential expression of alpha-galactosyl residues. Am J Trop Med Hyg 2012, 87:87-96.

10. Kamhawi S, Ramalho-Ortigao M, Pham VM, Kumar S, Lawyer PG, Turco SJ, Barillas-Mury C, Sacks DL, Valenzuela JG: A role for insect galectins in parasite survival. Cell 2004, 119:329-341.

11. Descoteaux A, Turco SJ: Glycoconjugates in Leishmania infectivity. Biochim Biophys Acta 1999, 1455:341-352.

12. Guimaraes-Costa AB, Nascimento MT, Froment GS, Soares RP, Morgado FN, Conceicao-Silva F, Saraiva EM: Leishmania amazonensis promastigotes induce and are killed by neutrophil extracellular traps. Proc Nat Acad SCi U S A 2009, 106:6748-6753.

13. Descoteaux A, Turco SJ, Sacks DL, Matlashewski G: Leishmania donovani lipophosphoglycan selectively inhibits signal transduction in macrophages. J Immunol 1991, 146:2747-2753.

14. Olivier M, Brownsey RW, Reiner NE: Defective stimulus-response coupling in human monocytes infected with Leishmania donovani is associated with altered activation and translocation of protein kinase C. Proc Natl Acad Sci U S A 1992, 89:7481-7485.

15. Winberg ME, Holm A, Sarndahl E, Vinet AF, Descoteaux A, Magnusson KE, Rasmusson B, Lerm M: Leishmania donovani lipophosphoglycan inhibits phagosomal maturation via action on membrane rafts. Microbes Infect 2009, 11:215-222.

16. Lodge $R$, Descoteaux A: Phagocytosis of Leishmania donovani amastigotes is Rac1 dependent and occurs in the absence of NADPH oxidase activation. Eur J Immuno/ 2006, 36:2735-2744.

17. Brittingham A, Mosser DM: Exploitation of the complement system by Leishmania promastigotes. Parasitol Today 1996, 12:444-447.

18. Vivarini Ade C, Pereira Rde M, Teixeira KL, Calegari-Silva TC, Bellio M, Laurenti MD, Corbett CE, Gomes CM, Soares RP, Silva AM, et al: Human cutaneous leishmaniasis: interferon-dependent expression of doublestranded RNA-dependent protein kinase (PKR) via TLR2. FASEB J 2011, 25:4162-4173.

19. Luz NF, Andrade BB, Feijo DF, Araujo-Santos T, Carvalho GQ, Andrade D, Abanades DR, Melo EV, Silva AM, Brodskyn Cl, et al: Heme oxygenase-1 promotes the persistence of Leishmania chagasi infection. J Immunol 2012, 188:4460-4467.

20. Proudfoot L, Nikolaev AV, Feng GJ, Wei WQ, Ferguson MA, Brimacombe JS, Liew FY: Regulation of the expression of nitric oxide synthase and leishmanicidal activity by glycoconjugates of Leishmania lipophosphoglycan in murine macrophages. Proc Natl Acad Sci U S A 1996, 93:10984-10989.

21. Coelho-Finamore JM, Freitas VC, Assis RR, Melo MN, Novozhilova N, Secundino NF, Pimenta PF, Turco SJ, Soares RP: Leishmania infantum: lipophosphoglycan intraspecific variation and interaction with vertebrate and invertebrate hosts. Int J Parasitol 2011, 41:333-342.

22. Assis RR, Ibraim IC, Noronha FS, Turco SJ, Soares RP: Glycoinositolphospholipids from Leishmania braziliensis and L. infantum: modulation of innate immune system and variations in carbohydrate structure. PLoS Negl Trop Dis 2012, 6:e1543.

23. Soares RP, Macedo ME, Ropert C, Gontijo NF, Almeida IC, Gazzinelli RT, Pimenta PF, Turco SJ: Leishmania chagasi: lipophosphoglycan characterization and binding to the midgut of the sand fly vector Lutzomyia longipalpis. Mol Biochem Parasitol 2002, 121:213-224.

24. Soares RP, Cardoso TL, Barron T, Araujo MS, Pimenta PF, Turco SJ: Leishmania braziliensis: a novel mechanism in the lipophosphoglycan regulation during metacyclogenesis. Int J Parasitol 2005, 35:245-253.

25. McConville MJ, Ferguson MA: The structure, biosynthesis and function of glycosylated phosphatidylinositols in the parasitic protozoa and higher eukaryotes. Biochem J 1993, 294(Pt 2):305-324.

26. Orlandi PA Jr, Turco SJ: Structure of the lipid moiety of the Leishmania donovani lipophosphoglycan. J Biol Chem 1987, 262:10384-10391.

27. Dubois M, Gilles K, Hamilton JK, Rebers PA, Smith F: A colorimetric method for the determination of sugars. Nature 1951, 168:167. 
28. Kolodziej H, Radtke OA, Kiderlen AF: Stimulus (polyphenol, IFN-gamma, LPS)-dependent nitric oxide production and antileishmanial effects in RAW 264.7 macrophages. Phytochemistry 2008, 69:3103-3110.

29. Lien E, Sellati TJ, Yoshimura A, Flo TH, Rawadi G, Finberg RW, Carroll JD, Espevik T, Ingalls RR, Radolf JD, Golenbock DT: Toll-like receptor 2 functions as a pattern recognition receptor for diverse bacterial products. J Biol Chem 1999, 274:33419-33425.

30. Delude RL, Yoshimura A, Ingalls RR, Golenbock DT: Construction of a lipopolysaccharide reporter cell line and its use in identifying mutants defective in endotoxin, but not TNF-alpha, signal transduction. J Immunol 1998, 161:3001-3009.

31. Drapier JC, Wietzerbin J, Hibbs JB Jr: Interferon-gamma and tumor necrosis factor induce the L-arginine-dependent cytotoxic effector mechanism in murine macrophages. Eur J Immunol 1988, 18:1587-1592.

32. Shapiro S, Wilk M: An analysis of variance test for normality (complete samples). Biometrika 1950, 52:591-611.

33. Kaye $P$, Scott P: Leishmaniasis: complexity at the host-pathogen interface. Nat Rev Microbiol 2011, 9:604-615.

34. de Veer MJ, Curtis JM, Baldwin TM, DiDonato JA, Sexton A, McConville MJ, Handman E, Schofield L: MyD88 is essential for clearance of Leishmania major: possible role for lipophosphoglycan and Toll-like receptor 2 signaling. Eur J Immunol 2003, 33:2822-2831.

35. de Assis RR, Ibraim IC, Nogueira PM, Soares RP, Turco SJ: Glycoconjugates in New World species of Leishmania: polymorphisms in lipophosphoglycan and glycoinositolphospholipids and interaction with hosts. Biochim Biophys Acta 1820, 2012:1354-1365.

36. Acosta-Serrano A, Almeida IC, Freitas-Junior LH, Yoshida N, Schenkman S: The mucin-like glycoprotein super-family of Trypanosoma cruzi: structure and biological roles. Mol Biochem Parasitol 2001, 114:143-150.

37. Watanabe H, Numata K, Ito T, Takagi K, Matsukawa A: Innate immune response in Th1- and Th2-dominant mouse strains. Shock 2004, 22:460-466

38. Mosser DM, Edwards JP: Exploring the full spectrum of macrophage activation. Nat Rev Immunol 2008, 8:958-969.

39. Silveira FT, Lainson R, De Castro Gomes CM, Laurenti MD, Corbett CE: Immunopathogenic competences of Leishmania (V.) braziliensis and L. (L.) amazonensis in American cutaneous leishmaniasis. Parasite Immunol 2009, 31:423-431.

40. Mahoney AB, Sacks DL, Saraiva E, Modi G, Turco SJ: Intra-species and stage-specific polymorphisms in lipophosphoglycan structure control Leishmania donovani-sand fly interactions. Biochemistry 1999, 38:9813-9823.

41. Vargas-Inchaustegui DA, Tai W, Xin L, Hogg AE, Corry DB, Soong L: Distinct roles for MyD88 and Toll-like receptor 2 during Leishmania braziliensis infection in mice. Infect Immun 2009, 77:2948-2956.

42. Becker I, Salaiza N, Aguirre M, Delgado J, Carrillo-Carrasco N, Kobeh LG, Ruiz A, Cervantes R, Torres AP, Cabrera N, et al: Leishmania lipophosphoglycan (LPG) activates NK cells through toll-like receptor-2. Mol Biochem Parasitol 2003, 130:65-74

43. Tuon FF, Amato VS, Bacha HA, Almusawi T, Duarte MI, Amato Neto V: Toll-like receptors and leishmaniasis. Infect Immun 2008, 76:866-872.

44. Flandin JF, Chano F, Descoteaux A: RNA interference reveals a role for TLR2 and TLR3 in the recognition of Leishmania donovani promastigotes by interferon-gamma-primed macrophages. Eur J Immunol 2006, 36:411-420

45. Kropf P, Freudenberg MA, Modolell M, Price HP, Herath S, Antoniazi S, Galanos C, Smith DF, Muller I: Toll-like receptor 4 contributes to efficient control of infection with the protozoan parasite Leishmania major. Infect Immun 2004, 72:1920-1928.

46. Junghae M, Raynes JG: Activation of p38 mitogen-activated protein kinase attenuates Leishmania donovani infection in macrophages. Infect Immun 2002, 70:5026-5035.

47. Singh RK, Pandey HP, Sundar S: Visceral leishmaniasis (kala-azar): challenges ahead. Indian J Med Res 2006, 123:331-344.

doi:10.1186/1756-3305-6-54

Cite this article as: Ibraim et al:: Two biochemically distinct lipophosphoglycans from Leishmania braziliensis and Leishmania infantum trigger different innate immune responses in murine macrophages. Parasites \& Vectors 2013 6:54.

\section{Submit your next manuscript to BioMed Central and take full advantage of:}

- Convenient online submission

- Thorough peer review

- No space constraints or color figure charges

- Immediate publication on acceptance

- Inclusion in PubMed, CAS, Scopus and Google Scholar

- Research which is freely available for redistribution 